\title{
Laboratory diagnosis of HIV infection
}

\author{
MV O'SHAUGHNESSY PhD, S CASSOL PhD
}

\begin{abstract}
MV O'Shaughnessy, S CASSOL. Laboratory diagnosis of HIV infection. Can J Infect Dis 1994;5(Supp1 E):7E-12E. The laboratory diagnosis of HIV infection has progressed greatly since the introduction of the commercially prepared HIV antibody assay in 1985. However, the antibody assay remains the gold standard since the sensitivity and specificity of properly performed tests exceed 99\%. Recent progress in diagnostic test development includes the availability of reliable HIV p-24 antigen capture assays with improved sensitivity due to the elimination of immune complexes of antibody and p-24 antigen and enhanced specificity due to the availability of confirmatory (neutralizing) reagents. HIV culture procedures have been optimized and standardized with isolation rates of the virus from HIV antibody positive persons approaching $95 \%$. This technology is labour intensive and requires special containment facilities. The polymerase chain reaction, and other amplification methods, such as the branched chain reaction, are used to search for the presence of HIV genetic information. These technologies are exquisitely sensitive but offer little routine advantage to the standard HIV antibody assay. There are specific circumstances, such as the diagnosis of perinatal infections and measuring the efficacy of potential agents for the treatment of HIV disease, where this technology is appropriate. The unique performance characteristies of these two amplification procedures necessitate that they be performed only in laboratories with adequate physical facilities and ongoing quality assurance programs. Assays for determining the antiviral sensitivity of HIV to specific drugs and for phenotyping viral isolates have been developed in research centres and are presently being introduced into clinical laboratories across Canada.
\end{abstract}

Key Words: AIDS, Human immunodeficiency virus, Laboratory tests, Molecular diagnoses. Serological diagnoses

\section{Épreuves de laboratoire pour le diagnostic de l'infection au VIH}

RÉSUMÉ : Les épreuves diagnostiques effectuées en laboratoire pour dépister l'infection au VIH ont grandement progressé depuis l'arrivée de tests de dépistage de l'anticorps anti-vIH préparés commercialement en 1985. Et ces tests demeurent l'étalon or, puisque leur degré de sensibilité et de spécificité, lorsqu'ils sont bien effectués, excèdent les $99 \%$. Les récents progrès accomplis en matière de mise au point de produits diagnostiques comprennent des épreuves plus fiables de captation de l'antigène p-24 du VIH, avec sensibilité améliorée à cause de l'élimination des complexes immuns de l'anticorps et de l'antigène p-24 et spécificité accrue due à la disponibilité de réactifs de confirmation (neutralisation). Les techniques de culture du viH ont été améliorées et standardisées, avec des taux d'identification du virus de près de $95 \%$ chez les personnes VIH-positives. Cette technologie est exigeante et requiert des installations spéciales. Les réactions de polymérisation en chaîne et autres méthodes d'amplification, comme les réactions en chaine ramifiées, sont utilisées pour vérifier la présence d’informations génétiques relatives au viH. Ces technologies sont très précises, mais offrent peu d'avantages sur le plan des épreuves de routine en comparaison avec les êpreuves de dépistage standard pour l'anticorps anti-viH. Dans certaines circonstances spécifiques, comme le diagnostic des infections périnatales et la mesure de l'efficacité d'agents thérapeutiques potentiels contre la maladie au viH, cette technologie pourrait être appropriée. Les caractéristiques uniques de ces deux techniques d'amplification sur le plan du rendement exigent qu'elles soient effectuées uniquement dans des laboratoires dotés d'installations matérielles adéquates et de programmes permanents d'assurance de la qualité. Des épreuves visant à déterminer la sensibilité anti-virale du viH à certains médicaments et au phénotypage des isolats viraux ont été mises au point dans des centres de recherche et font présentement leur entrée dans des laboratoires cliniques un peu partout au Canada.

British Columbia Centre for Excellence in HIV/AIDS and Department of Pathology. St Pauls Hospital; and the University of British Columbia, Vancouver, British Columbia

Correspondence and reprints: Dr MV O'Shaughnessy, British Columbia Centre for Excellence in HIV/AIDS, St Pauls Hospital. Room 613, 1081 Burrard Street, Vancouver, British Columbia V6Z 1Y6. Telephone (604) 631-5477, Fax (604) 631-5135 
$\mathrm{T}$ HE SPECIFIC LABORATORY DIAGNOSIS OF HIV INFECTION began in 1984 with the publications from the United States National Institutes of Health (NIH) describing the development of an enzyme immunoassay (EIA) test for the detection of antibodies to HIV and methods for the isolation of the virus in tissue culture (then designated HTLV-III) $(1,2)$. These early procedures represented major breakthroughs, since the lack of specific assays had impeded natural history, epidemiological and clinical investigations of HIV infection.

These early assays had relatively good sensitivity and could detect anti-HIV antibodies in approximately $95 \%$ of individuals with HIV disease. However, they performed quite poorly in detecting low levels of anti-HIV antibody, a situation encountered early during the process of seroconversion and in samples collected from those in late stage immunodeficiency.

These tests suffered from problems of low specificity, most likely due to the significant amount of contaminating cellular proteins present in the antigen preparation used to coat the microtitre plates. Hence, when populations at low risk for HIV infection were tested by these assays, more than $90 \%$ of the EIA reactive sera did not contain antibodies specifically directed against HIV. However Gallo et al $(2,3)$ at NIH and others recognized this inherent lack of specificity and used a second assay, the Western or immunoblot, to verify the screen test (EIA) results. This procedure had been a research tool until that time and Gallo's report helped introduce these research or high technology (for 1984) procedures into routine testing algorithms.

Neither screening nor confirmatory procedures were commercialized in 1984, and the situation remained that way until November 1985, when commercial EIAS were approved for sale in Canada. However, the in- house assays were introduced into Canada in July 1984 and sera collected under specific criteria were tested during the fall of that year. Before the introduction of commercial tests, the assays performed irregularly and much time was devoted to retesting samples because tests performed unsatisfactorily. The entire procedure was manual including coating the inactivated viral antigens onto the microtitre plates and the preparation of the signal enzyme and substrate. Approximately $20 \%$ of the assays gave inconclusive results and had to be repeated.

Confirmatory assays were not commercially available for two to three years after testing by EIA began. The original immunoblots used at the Laboratory Centre for Disease Control in Ottawa were prepared with antigens purchased from various commercial suppliers. The antigen preparations were highly variable, and there was little consistency in the different viral specific proteins present, the amount of contaminating cellular proteins in the antigen preparation, and the relative ratios of one viral protein to another. Later, as commercial immunoblots became available, most of these difficulties were resolved. The major impediment to the use of these commercial blots was the price: the original cost was approximately \$50 per strip. The cost of material prepared in-house, which suffered from all of the problems listed above, was $20 \%$ that of the commercial product.

Another impediment encountered at that time was the lack of consensus concerning the definition of HIV antibody positivity. A preliminary consensus defining positivity was not reached until late 1985. Since the process of seroconversion was so poorly understood, there was considerable confusion as to the meaning of immunoblot results in which the sera demonstrated reactivity to only the $\mathrm{p}-24$ antigen band. Subsequent

TABLE 1

Characteristics of assays used in the laboratory diagnosis of HIV infection

\begin{tabular}{|c|c|c|c|}
\hline Assay & Sensitivity & Specificity & Comments \\
\hline HIV antibody screen test & High & High & $\begin{array}{l}\text { In low risk populations the ratio of false positives:true positives may be } \\
3: 1 \text { using third-generation EIA tests. First- and second-generation } \\
\text { assays performed poorly }\end{array}$ \\
\hline HIV p-24 capture assay & Moderate & Moderate & $\begin{array}{l}\text { The introduction of the immune complex dissociation step has } \\
\text { improved the sensitivity of the assay, but it remains low. All results on } \\
\text { patient samples must be confirmed by neutralization }\end{array}$ \\
\hline HIV culture & Moderate & Moderate & $\begin{array}{l}\text { Repeat samples may have to be tested before successful isolation of } \\
\text { virus. Cross-contamination has been reported to be a problem in } \\
\text { some laboratories }\end{array}$ \\
\hline
\end{tabular}

High sensitivity includes assays with at least $95 \%$ sensitivity, and medium sensitivity ranges from 50 to $95 \%$. The same ranges are used with respect to specificity. The performance characteristics are those obtained from the most recent modifications of the various kits or procedures. ElA Enzyme immunoassay 
TABLE 2

Alternative specimens used for HIV testing

\begin{tabular}{|c|c|c|}
\hline Alternative samples & Uses & Comments \\
\hline Dried blood spots & $\begin{array}{l}\text { HIV antibody testing: PCR } \\
\text { detection and } \\
\text { characterization of HIV }\end{array}$ & $\begin{array}{l}\text { Specific modifications have been made to HIV antibody kits to } \\
\text { accommodate dried blood spot antibody testing }\end{array}$ \\
\hline Whole blood & $\begin{array}{l}\text { HIV detection by PCR } \\
\text { Culture }\end{array}$ & $\begin{array}{l}\text { Commercial kits are still not routinely available, but one has been submitted } \\
\text { to the Food and Drug Administration in the United States for review } \\
\text { HIV can be isolated from unseparated whole blood and this procedure has } \\
\text { been used to demonstrate virus in small aliquots of blood obtained from } \\
\text { newborns } \\
\text { Some commercial products do not require separation of blood }\end{array}$ \\
\hline
\end{tabular}

PCR Polymerase chain reaction

information demonstrated that most of the individuals who were reactive to only this single antigen were not infected with HIV, and these samples were eventually labelled as indeterminate, that is, neither positive nor negative. However, some individuals in the process of seroconverting to HIV had a similar pattern of reactivity, that is, antibody to only the p-24 antigen. Sorting out these two groups was problematic, and for a short time in 1984-85 there was considerable imprecision in the reporting of results. A Canadian consensus definition of positivity was reached in Vancouver in 1986. Table 1 summarizes the tests available for the detection of either HIV or antibody directed against HIV. The sensitivities and specificities of these tests are presented, as are comments regarding the performance.

During those early years there was considerable debate as to the performance of the screen assays, but these first-generation assays performed well if they were directly compared with other diagnostic assays commonly in use at that time. Sensitivity and specificity of the HIV test actually exceeded $95 \%$, which was exceptional for a test that was prepared in individual laboratories. More than 30,000 samples were tested using these early prototype assays in the Laboratory Centre for Disease Control.

The arrival of the commercial EIAs onto the market in 1985 represented a breakthrough since these assays were easy to use and the results were reproducible. When first introduced they were inordinately expensive, but their price has dropped dramatically as the competition has increased. The screen test now costs approximately $\$ 0.90$, compared with the $\$ 4$ to $\$ 5$ range eight years ago.

There are now alternatives to using the standard immunoblot for verification of screen test positivity. In the United States there is a commercial immunofluorescence assay available for use as a supplemental assay, and many investigators no longer use immunoblot to confirm results for epidemiological studies. Often combining two simple assays - such as ElA - in tandem, using a second EiA test to confirm the reactivity detected in the orignal screening test, will not result in the loss of significant performance, but will reduce the costs of confirmatory assays by more than $80 \%$. Many groups have successfully employed this strategy when testing samples in unlinked, anonymous research protocols (4).

HIV antibody testing has changed greatly in the past four or five years. Third-generation ELA assays employ either peptides or recombinant antigens to capture the HIV antibody, thereby increasing the specificity of the assay as well as the sensitivity. The original ElAs were deficient in detecting low levels of anti-HIV antibody in the window phase, that is, shortly after infection. The new generation of commercial assays now can detect antibody as soon as 10 days after infection. In addition, many advances have been made in the types of samples that can be tested for HIV antibody. The first major breakthrough occurred with the demonstration that there was sufficient antibody in dried blood spots for eluates to be tested for HIV antibody without any significant compromise in test performance (5). Saliva has been shown to contain sufficient immunoglobulin to permit its use in testing for HIV antibody in research studies (6). Canadians developed strategies using both modified test protocols and different body fluids in screening for antibodies to HIV and these procedures are now widely used throughout the world. Table 2 summarizes the use of alternative specimens for the direct detection of HIV or the demonstration of anti-HIV antibody.

All these early diagnostic assays detected antibody to HIV produced following infection with the virus. The detection of antibody is an indirect measure since the virus or its components are not specifically detected. In 
1984-85 there was acrimonious debate as to the meaning of antibody positivity. Were antibody-positive persons all infected with HIV or did many produce antibody in response to an agent cleared from their system? The answer was known in late 1985 when a study reported the successful isolation of virus from nearly all the HIV antibody-positive individuals studied (7).

The direct demonstration of HIV initially was reported following the recovery of virus from peripheral blood lymphocytes cocultivated in the presence of purified lymphocytes or T4-positive lymphocyte cell lines. Successful isolation of the virus was problematic because the technology had not been optimized and isolation was often in the range of 30 to $50 \%$. Incorporation of several technical refinements - improved transportation of samples; the use of primary, prestimulated cells for co-cultivation; and the development of commercially available p-24 antigen capture assay - all contributed to the present situation whereby virus can be isolated from virtually all HIV-positive persons.

Isolation of virus is only rarely required for diagnosis, but as evidence increases of the importance of viral resistance to the commonly used nucleoside analogues such as zidovudine (AZT) or didanosine (ddI) (8) we can expect requests for isolation and in vitro sensitivity assays to increase significantly.

Recent evidence supports the hypothesis that the phenotype of the virus is an important marker for disease progression. HIV that induces the formation of syncytia when cultured in the presence of MT-2 cells is thought to represent a highly virulent form of the virus (9). Progression in individuals with syncytia-inducing virus (SI) is rapid, while individuals with nonsyncytiainducing virus (NSI) progress more slowly (10). It appears the infecting virus is principally the Nsi type, but SI virus predominates as disease progresses. Vaccine trials will require that virus isolation programs be enacted. It will be critical to obtain information on the predominating virus present in communities in which vaccine trials occur; the phenotypic and genotypic composition of any virus that breaks through the protective effect of the candidate vaccine; and the characterization of the immune response - both cellular and humoral of the vaccinees to the vaccine strains and to the predominating virus.

Occasionally, the isolation of HIV from specimens does provide useful diagnostic information. For example, in investigations of vertical transmission of HIV, virus isolation can provide a definitive diagnosis of HIV infection in the majority of infected children by the time they are six weeks old (11). This is an important consideration: serological assays do not provide an unequivocal answer because children born to HIV-positive mothers retain passively transferred anti-HIV antibodies for up to 18 months of age (12).

The detection of HIV p-24 antigen (capsid antigen) in body fluids has proven to be a very useful tool in specific circumstances. The original commercial protocols lacked the ability to detect p-24 antigen bound in immune complexes, but the introduction of an acid dissociation step, in which the immune complexes of antigen and its homologous antibody are cleaved by treating with acid, has improved the sensitivity of the procedure (13). The technique is often used to monitor cell cultures for the presence of HIV and is ideally suited for that purpose. The p-24 antigen capture has practically replaced the reverse transcriptase assay for monitoring virus infection in vitro, and the ability to provide verification of results by introducing a neutralization assay has significantly improved the specificity of the procedure.

The utility of this assay for the diagnosis of HIV infection is limited (14), but there are several specific circumstances in which it is particularly applicable. During the window phase of infection, that is, the interval between infection and the production of detectable antibodies to HIV, the sera or plasma taken from infected persons may test positive for p-24 antigen. Consequently, the HIV antibody-negative person may be demonstrated to be infected by this virus. A significant proportion of individuals in the window phase will be p-24 antigen-positive. Fortunately, the length of the window phase has been decreased with the introduction of more sensitive EIA tests. These commercial kits most often use recombinant proteins or peptides as their capture antigens and resulting interval of antibody negativity has been reduced. In fact, the utility of the antigen capture assay as a first line diagnostic is largely related to the questions being asked. For example, in low incidence areas, such as Canada, the United States and parts of Western Europe, studies have demonstrated that the screening of blood donations for $\mathrm{p}-24$ antigen does not add a real benefit in terms of removing HIV-positive units from the blood supply. However, localities with very high incidence of HIV infection in blood donors - that is, many individuals in the window phase of infection and lacking detectable HIV-specific antibody - may have to reassess their particular situation. This would involve testing a study population for both HIV antibody and antigen. If there were a large number of individuals discovered to be in the window phase, perhaps the most economical strategy would be to focus on donor recruitment rather than implementing a costly p-24 detection program with a sensitivity of about $50 \%$.

There are two uses of HIV antigen detection that are noteworthy. The first one is clinical trials. As HIV disease progresses, the probability of HIV antigenemia increases. Consequently, some clinical trials have used the disappearance of p-24 antigenemia as a surrogate marker (rather than clinical end-points) for drug efficacy (15). The limitation of this strategy is that enrolment in these trials has been restricted to individuals who enter the trial antigen-positive. Future trials will most likely not rely on this marker because newer 
technology, for example the polymerase chain reaction (PCR), is many times more sensitive than antigen capture. The second situation in which the antigen capture assay has particular relevance is in determining the HIV status of children born to HIV-positive mothers (16). These children are all HIV antibody-positive since they passively acquire antibodies in utero. Approximately $20 \%$ of the children born to HIV-positive mothers will be infected but 100\% are antibody-positive. The differentiation of the infected from the noninfected can be technically demanding and time consuming since the infant may not produce an antibody signature until 15 to 18 months of age. The isolation of virus proves infection but this technology does have some limitations. The transportation of specimens can be problematic, especially if air transport is involved, and not all centres have the required biocontainment facilities or expertise to recover HIV from peripheral blood lymphocytes. Additionally, virus may not be readily isolated from all HIV-infected persons. Consequently, the demonstration that a child born to an HIV-positive mother is p-24 antigen-positive (if the result is confirmed by a neutralization step) is proof that perinatal transmission of HIV has occurred and is a diagnostic option that should be used in these circumstances.

The last technology we will discuss is the detection of the genetic information of the virus. The application of molecular biology to the diagnostic laboratory is a new phenomenon but it has implications that are very far reaching. Originally evidence was presented indicating that very few peripheral lymphocytes were infected with HIV. These data were derived using the technique of hybridization in which labelled probes reacted with HIV RNA in T lymphocytes. These preliminary results suggested that one in 10,000 T lymphocytes were infected with HIV (17). The introduction of alternative methods, such as PCR, for detecting target nucleic acid sequences has led to a better understanding of the pathogenesis of HIV disease. These newer techniques have a much increased sensitivity over the conventional procedures because of the inherent amplification steps. In the PCR method the enrichment of the target sequence allows its concentration to increase by about $10^{6}$ (18). If viral sequences are present in low concentration, PCR allows the number of target molecules to be amplified and detection is then possible. The inherent sensitivity of this procedure has also been a major impediment to the general acceptance of this molecular biological tool. Problems of carry-over and cross-contamination of samples have always been recognized in the diagnostic laboratory, but this technology has heightened our awareness of these potential pitfalls. For example, a serum sample with a positive Western blot can often be diluted 100,000 times and still retain its positivity. On the other hand, one molecule of contaminating DNA will cause a false positive result when samples are analyzed by PCR. This type of laboratory error can be due to a droplet of sample containing a single molecule of DNA contaminating a nearby specimen. This can occur by not using a positive displacement pipetting device. The implementation of both vigorous quality assurance programs and technical improvements to reduce carry-over have mitigated concerns of the generation of false positive results.

The utility of such a powerful technology has been extensive. For example, the confirmation of vertical HIV transmission by serological means and/or culture is possible, but there are impediments to a definitive diagnosis and they have been discussed earlier. The detection of virus by PCR does not require the isolation of infectious HIV and the samples can be treated in order to inactivate this agent. Since this procedure can be used to search for target sequences of relatively stable DNA complementary to the viral genomic RNA, precautions relating to the stability of the targets can be minimized. The DNA need not be intact because the PCR can yield positive results even when the human genomic DNA has been fragmented. Usually PCR is used to amplify regions of genome with rather a limited size, ie, 250 to 500 bases in length. Since the reaction begins with the binding of nucleic acid primers - approximately 25 bases in length - the selection of these primers is a critical step. Primers lacking homology to common strains of HIV will have a low sensitivity, while primers that cross-react with normal human genome will have low specificity. To improve specificity more than one primer set is usually chosen, and the use of primers to pairs of highly conserved regions of viral specific genes, such as gag + envelope or gag + polymerase, is standard practice.

This technology has been used for several specific purposes. The high sensitivity of the assay has been optimized for the detection of vertically transmitted HIV (19). Virus is generally detected within the first two weeks following birth and has even been detected when DNA has been extracted from dried blood spots collected onto filter papers (20). This later adaption facilitates the shipment of samples around the world and reduces the possibility of incurring accidents. The DNA on these dried blood spots is stable and is in sufficient quantity to permit more extensive genetic analyses than just detection (21).

Another recent application of this technology is the quantification of virus present in the plasma (22). This can be an important exercise because clinical trials of antiretroviral agents require such a measure to be made with precision and reproducibility. Estimating the amount of virus circulating by enumerating virus that can be co-cultivated is often imprecise and poorly reproducible. Estimation of the amount of virus circulating has been reported using RNA PCR, which detects and quantifies the number of genomes present. Hence, if an antiretroviral agent has been successful in reducing the production of progeny virus the numbers of virions detect- 
able in the plasma should decrease with treatment. Common drugs such as AZT seem to have little effect on the numbers of infected cells (they do not cure the infection) but they have been demonstrated to reduce the amount of free virus found in the circulatory system, albeit for a limited duration.

This technique can be used for the detection of virus resistant to the action of antiretroviral agents. The technology can be modified so that specific mutations in the polymerase gene are probed for using modified PCR primers. PCR has been adapted for use in a microtitre assay constructed to screen clinical isolates directly for the growth of virus in the presence of the antiretroviral drug (23). With the emergence of data on the role of drug resistance in the progression of disease in treated individuals, this application of PCR will be expanded and refined.

\section{REFERENCES}

1. Gallo RC, Salahuddin SZ, Popovic M, et al. Frequent detection and isolation of cytopathic retrovirus (HTLV-III) from patients with AIDS and it risk for AIDS. Science 1984;224:500-3.

2. Sarngadharan MG, Popovic M, Bruch L, et al. Antibodies reactive with human T-lymphotropic retroviruses (HTLV-III) in the serum of patients with AIDS. Science 1984;224:506-8.

3. Gallo D, Diggs JL, Shell GR. Comparison of detection of antibody to the acquired immunodeficiency syndrome virus by enzyme irnmunoassay, immunoflourescence and Western blot methods. J Clin Microbiol 1986;23:1049-51.

4. Lepine D, Neumann PW, O'Shaughnessy MV. Evaluation of an HIV test algorithm utilizing a recumbent protein enzyme immunoassay. J Clin Microbiol 1990;28:1169-71.

5. Hoff R, Berarde VP, Weiblen BJ, et al. Seroprevolence of human immunodeficiency virus among childbearing women. N Engl J Med 1988;318:525-30.

6. Major C, Read S, Coates R, et al. Comparison of saliva and blood for human immunodeficiency virus prevalence testing. J Infect Dis 1991;163:699-702.

7. Levy JA, Shimabakuro J. Recovery of AIDS associated retroviruses from patients with AIDS related conditions and clinically healthy individuals. J Infect Dis 1985;152:734-8.

8. Wainberg MA, Tremblay M, Rooke R, et al. Characterization of reverse transcriptase activity and susceptability to other nucleosides and zidovudine resistant variants of HIV-1 results from the multi centre. Canadian Zidovudine Study. Ann NY Acad Sci 1990;616:346-55.

9. Boucher CA, Lange JMA, Miedema FF, et al. HIV-1 biological phenotype and the development of zidovudine resistance in relation to disease progression in asymptomatic individuals during treatment. AIDS 1992;6: 1259-64.

10. Koot M, Keet IP, Vos AH, et al. Prognostic value of HIV-1 syncytium-inducing phenotype for the rate of CD4 cell depletion and progression to AIDS. Ann Intern Med 1993; 1 18:681-8.

11. Borkowsky W, Krasinski K, Pollack H, et al. Early diagnosis of human immuno-deficiency virus in children $<6$ months of age comparison of polymerase chain
This same technology is also being used to group virus isolates in various families on the basis of the genetic relatedness of one virus to another (24). Sequences from specific regions, usually gag or envelope, of the viral genomes are compared, and family trees are built on the similarity or dissimilarity of one isolate to another. This type of research will play a large role when vaccine trials begin, as virus that breaks through the protective effect of a candidate vaccine must be fully characterized.

The laboratory tools available for the diagnosis of HIV infection are remarkably diverse and complimentary. HIV, as a retrovirus, has provided us with diagnostic dilemmas, but the molecular biology laboratory has been the development site for many of the tools now used for routine laboratory diagnosis of HIV infection.

reaction, culture and plasma antigen cystine techniques. J Infect Dis 1992;166:616-9.

12. Lambert JS, Maternal-fetal transmission of HIV-1 infection. Pediatr Ann 1992:22:413-6.

13. Bollinger RC, Kline RL, Francis HL, et al. Acid dissociation increases in sensitivity of p24 antigen detection for the evaluation of antiviral therapy and disease progression in asymptomatic HIV infected person. $\mathrm{J}$ Infect Dis 1992;165:913-6.

14. Polk BF, Fox R, Brookmeyer R, et al. Progression of AIDS developing in a cohert of seropositive homosexual men. N Engl J Med 1987;316:61-6.

15. Constantine NT. Serologic tests for retroviruses approaching a decade of evolution. AIDS 1993;7:1-13.

16. Tovo PA, Gabiano C, Riva C, et al. Specific antibody and virus antigen expressed in congenital HIV infection. Lancet 1987;i:1201.

17. Harper ME, Marselle LM, Gallo RC, et al. Detection of lymphocytes expressing human T-cell lymphotropoc virus in lymph notes and peripheral blood from infected individuals by in-situ hybridization. Proc Natl Acad Sci USA 1986;83:772-6.

18. Mullis KB, Faloona FA. Specific synthesis of DNA in vitro via a polymerase-catalyzed chain reaction. Methods Enzymol 1987; 155:335-50.

19. Cassol S, Salas T, Arella M, et al. Use of dried blood spots in the detection of human immunodeficiency virus type 1 by the polymerase chain reaction. J Clin Microbiol 1991;29:667-71.

20. Cassol S, Lapointe N, Salas T, et al. Diagnosis of vertical HIV-1 transmission using the polymerase chain reaction and dried blood spot specimen. J Acquir Immune Defic Syndr 1992;3:113-9.

21. Cassol S, Salas T, Arella M, et al. Stability of dried blood spot specimens for the detection of HIV/DNA by PCR. J Clin Microbiol 1992;30:3039-42.

22. Piatak M, Saag MS, Vang LC, et al. High levels of HIV-1 in plasma during all stages of infection determined by competitive PCR. Science 1993;259:1749-54.

23. Conway B, Ko D, Foss N, et al. PCR based anti-viral susceptibility testing. Can J Infect Dis 1992;3:22-3.

24. Myers G, Berzofsy JA, Korber B, et al. Human Retroviruses and AIDS. Los Alamos: Los Alamos National Laboratory, 1992. 


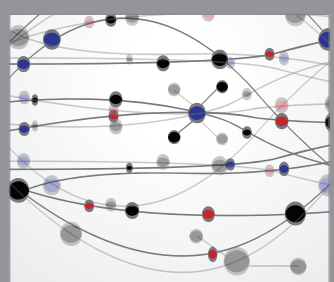

The Scientific World Journal
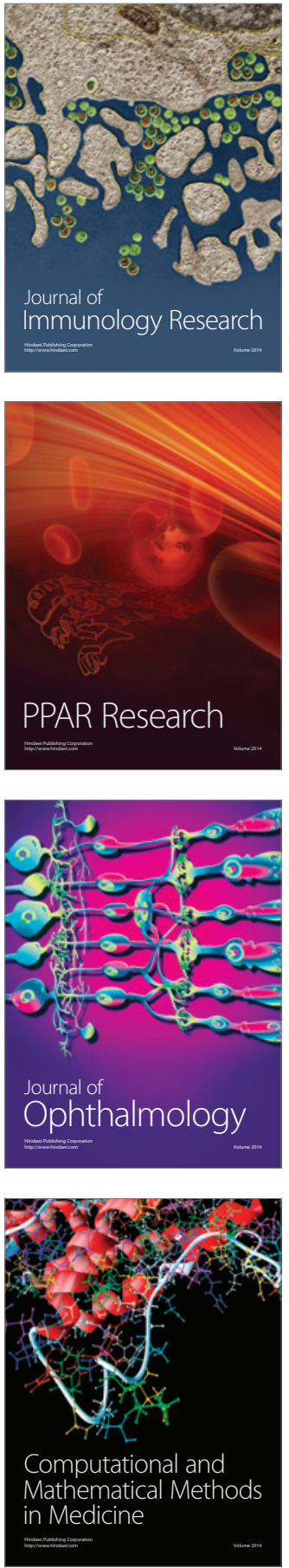

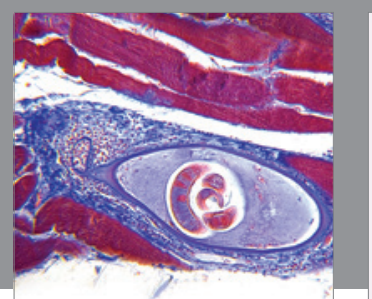

Gastroenterology Research and Practice

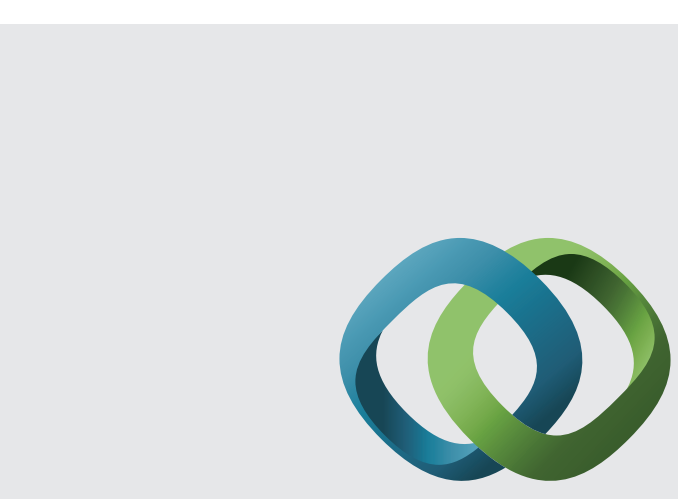

\section{Hindawi}

Submit your manuscripts at

http://www.hindawi.com
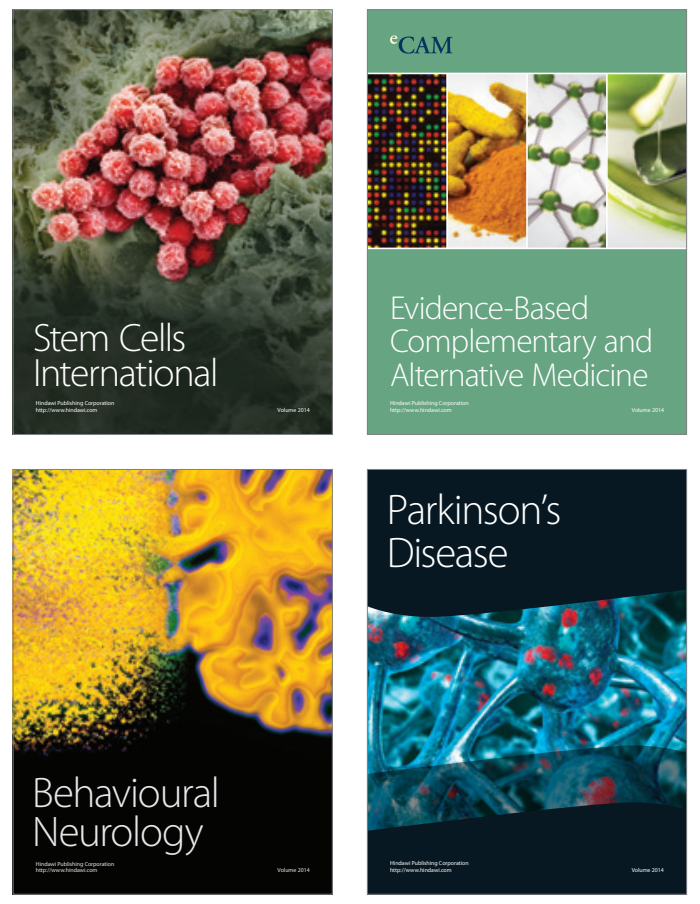
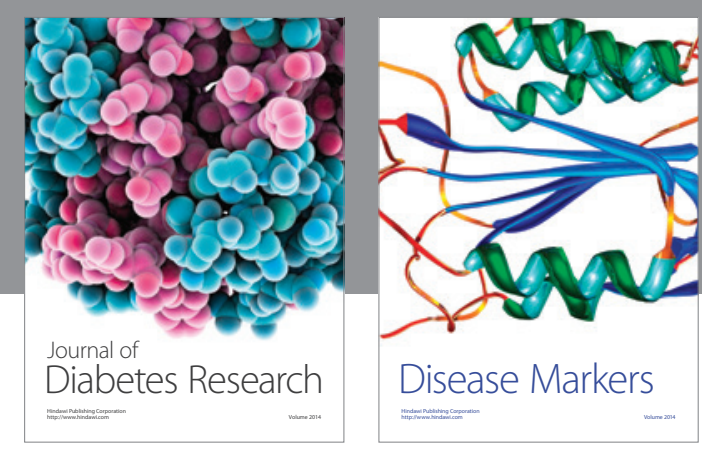

Disease Markers
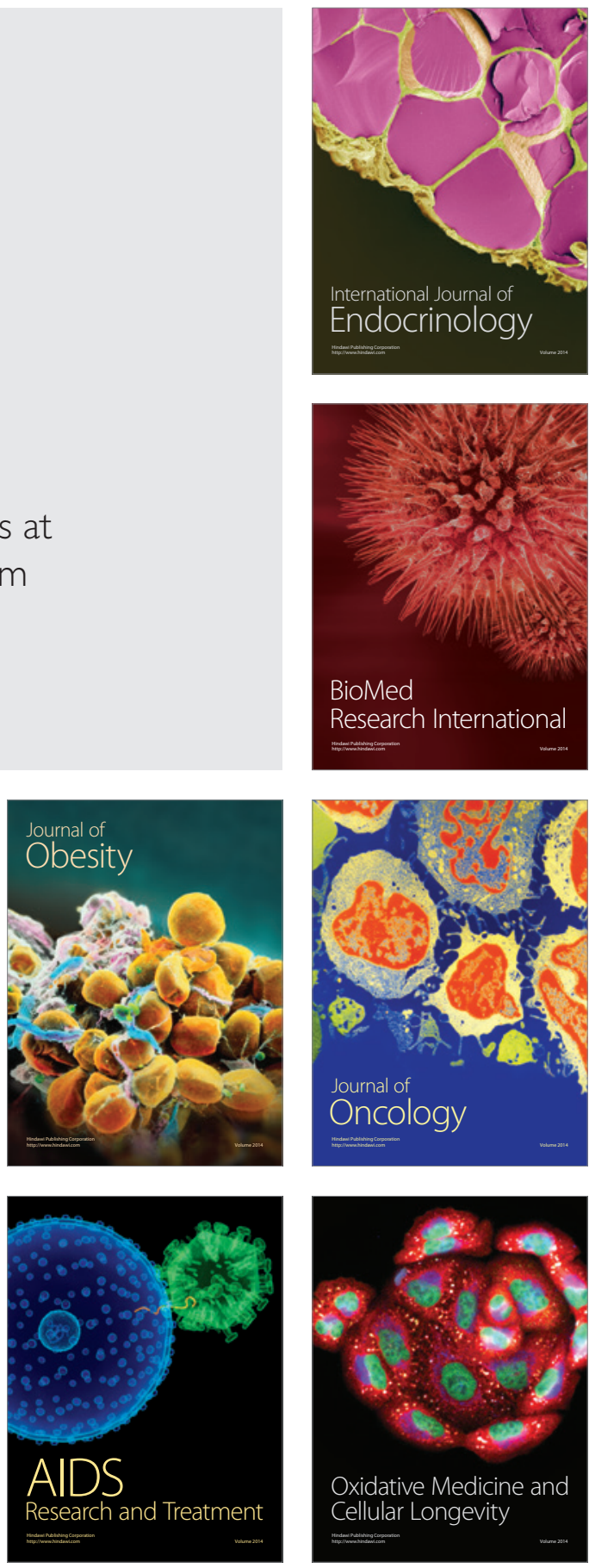